\title{
CORRESPONDENCE
}

\section{About the ERS logo}

\section{To the Editor:}

A logo is a very important feature of any association because it is a way of presenting in a simple image all the emotional significance of such a society. For members, the logo becomes a symbol that is loved and worthy-of-pride.

As a pneumologist and researcher in lung diseases, I recently joined the prestigious European Respiratory Society (ERS). An increasing feeling of affection for ERS is growing within me, and I know that in the near future I will be fully embedded in all that ERS represents. Before this occurs, and before the ERS logo becomes to me a highly emotional and beloved symbol, I want to comment on my first impression. I was very disappointed in relation to the ERS logo, in which it seems that the large airways enter the lungs through both apices and not through the hila! I can hardly justify that a society of pneumologists has a logo which is so anatomically distorted. I suggest to the ERS Executive Committee that they seriously consider some change in the ERS logo.

M.H. Vargas

Instituto Nacional de Enfermedades Respiratorias, Tlalpan 4502, CP 14080, México DF, México. 